\title{
Resistant starch does not affect zinc homeostasis in rural Malawian children
}

"Thaddaeus May*, ${ }^{\ddagger}$ Claire Westcott* ${ }^{*}$ Chrissie Thakwalakwa, ${ }^{*} \mathrm{M}$ Isabel Ordiz, ${ }^{+}$Ken Maleta, ${ }^{\ddagger}$ Jamie

Westcott, "Kelsey Ryan, 'K Michael Hambidge, ${ }^{\ddagger}$ Leland V. Miller, 'Graeme Young, ^Elissa Mortimer,

${ }^{\Re \#+}$ Mark J Manary, and ${ }^{\dagger}$ Nancy F Krebs

"Department of Pediatrics, Baylor College of Medicine, Houston, TX, 77030

${ }^{\ddagger}$ Department of Pediatrics, University of Colorado School of Medicine, Aurora, Colorado 80045

${ }^{+}$Community Health Department, College of Medicine, University of Malawi, Blantyre, Malawi

${ }^{\wedge}$ Flinders University

\#Department of Pediatrics, Washington University in St. Louis, St. Louis, MO 63130

*Both authors contributed equally to the manuscript.

To whom correspondence should be addressed: Mark Manary, Department of Pediatrics, St. Louis

Children's Hospital, One Children's Place, St. Louis, MO 63110 manary@kids.wustl.edu

This study was supported by the Bill \& Melinda Gates Foundation, Child Health Research Internship, Children's Hospital Colorado Research Institute, and NIH K24 DK083772. The sponsors played no role in the study design, data collection or data analyses.

The trial was registered with ClinicalTrials.gov under the protocol number NCT01811836.

Word count: $2920 \quad$ Number of Tables: $3 \quad$ Number of Figures: 1 


\begin{abstract}
Objective: This study tested the hypothesis that Malawian children at risk for zinc deficiency will have reduced endogenous fecal zinc (EFZ) and increased net absorbed zinc (NAZ) following the addition of high amylose maize resistant starch (RS) to their diet.
\end{abstract}

Methods: This was a small controlled clinical trial to determine the effects of added dietary RS on zinc homeostasis among 17 stunted children, aged 3-5 years consuming a plant-based diet and at risk for perturbed zinc homeostasis. Dual zinc stable isotope studies were performed before and after 28 days of intervention with RS, so that each child served as their own control. The RS was incorporated into fried wheat flour dough and given under direct observation twice daily for $28 \mathrm{~d}$. Changes in zinc homeostatic measures were compared using paired Student's t-Tests and linear regression analysis.

Results: Children had a mean height-for-age Z-score of -3.3 , and consumed animal source foods $\leq$ twice per month. Their habitual diet contained a phytate:zinc molar ratio of 34:1. Children avidly consumed the RS without complaints. EFZ was $0.8 \pm 0.4 \mathrm{mg} / \mathrm{d}$ (mean $\pm \mathrm{SD}$ ) both before and after the intervention. Fractional absorption of zinc was $0.38 \pm 0.08$ and $0.35 \pm 0.06$ before and after the RS intervention respectively. NAZ was $1.1 \pm 0.5$ and $0.6 \pm 0.7$ before and after the RS intervention. This reduction of NAZ corresponded with diminished dietary zinc intake on the study day following intervention with RS. Regression analysis indicated no change in zinc absorption relative to dietary intake as a result of the RS intervention.

Conclusion: Consumption of RS did not improve zinc homeostasis in rural African children without zinc deficiency. RS was well tolerated in this setting.

Key words: zinc, zinc absorption, endogenous zinc, zinc homeostasis, Malawi, resistant starch, high amylose maize starch, stunting 


\title{
BACKGROUND
}

Zinc deficiency affects tens of millions of children throughout the developing world, [1] and has been implicated in the pathogenesis of stunting [2], impaired cognitive development [3], and infectious morbidity [4,5]. Previous studies of zinc homeostasis among children in rural Malawi have demonstrated that perturbations of zinc homeostasis are related to the abundance of phytate in the diet, which is a primary inhibitor of zinc absorption [6-9], and impaired conservation of zinc secreted into the intestinal lumen, but not reabsorbed [10-14], known as endogenous fecal zinc (EFZ).

Resistant starch (RS) is present in cereals, tubers, legumes and some fruits. RS resists digestion in the small bowel resulting in increased colonic starch which serves as a substrate for the fermentative production of short chain fatty acids, which in animal models exert effects on colonic luminal pH and colonic microbiota profiles. In humans, RS and enhanced colonic short chain fatty acids have been reported to confer health benefits in patients with metabolic syndrome and inflammatory bowel disease [15-19]. It has also been speculated that RS may improve absorption of cationic minerals such as zinc, because of increases in particular bacterial enzymes, including acidic phytase [8,20-23]. High amylose maize starch contains larger quantities of RS than other cereal varieties [24], and is a common additive to many commercial food products [25]. In this study we tested the hypothesis that 3-5 year old rural Malawian children at risk for perturbed zinc homeostasis will have reduced EFZ and increased net absorbed zinc (NAZ) following addition of high amylose maize starch to the diet for $28 \mathrm{~d}$.

\section{METHODS}

\author{
Subjects
}


Eligible subjects were stunted children, aged 3-5 years, consuming animal source foods $\leq$ twice/month who resided in Masika, Malawi. Masika is an isolated village of subsistence farmers growing primarily maize, cassava, legumes, and rice. Residents live in mud huts with grass roofs, collect water from shallow wells, and travel over $50 \mathrm{~km}$ to reach the nearest paved road. The screening process consisted of an anthropometric assessment and a food frequency questionnaire. Stunting and infrequent consumption of animal source foods were chosen as eligibility criteria in order to select children at greater risk for perturbed zinc homeostasis $[26,27]$.

The study was approved by the College of Medicine Research and Ethics Committee at the University of Malawi, the Institutional Review Board from Washington University School of Medicine in St. Louis, and the University of Colorado Denver. Written and oral informed consent was obtained through a three step community-based process; 1) the entire community was informed about the study, 2) caretakers of potential participants attended a presentation about the study, and finally, 3) each caretaker individually provided consent for their child to participate.

\section{Study Design}

This was a small controlled clinical trial to determine the effects of dietary RS on zinc homeostasis. Subjects participated in a dual zinc stable isotope study before and after the intervention, so that each child served as his/her own control. The sample size of 20 children was chosen assuming that 18 children would successfully complete the dose administration and sample collection. The sample size was chosen to detect a $20 \%$ change in EFZ with $95 \%$ specificity and $80 \%$ power, assuming that variances would be similar to those of a previous village-based study in rural Malawi [27]. The primary outcomes were changes in EFZ and NAZ before and after intervention with RS, as measured by an isotope dilution method [28]. Secondary outcomes were changes in fractional absorption of zinc (FAZ), and total absorbed zinc (TAZ), before and after intervention with RS, measured by dual isotope 
tracer ratio method [29]. Neither subjects nor clinical research workers were blinded to the intervention. Laboratory personnel were blinded during analyses. The trial was registered with ClinicalTrials.gov under the protocol number NCT01811836.

\section{Participation}

On the first day of participation, caretakers completed a questionnaire detailing demographic and social characteristics of the child as well as sanitation and hygiene practices. Anthropometric measurements were made at this time. The zinc stable isotope study was started on day 1 and required 8 days to complete collection of specimens. Upon completion of the first stable isotope test the RS intervention was initiated. After 28 days of intervention with RS, an additional zinc stable isotope study was undertaken. The RS intervention was continued over the 8 days required for this second test. Anthropometric measurements were repeated on day 38. Total participation time for each child was 45 days.

\section{Study Intervention}

On study days $9-45$, participants were given $8.5 \mathrm{~g} / \mathrm{d}$ of RS which was added to a locally produced fried cake, known as a mandasi, comprised of white wheat flour, whole fluid milk, whole eggs, baking powder, salt, sugar, and soybean oil. The average weight of each mandasi was $40 \mathrm{~g}$, and provided approximately $150 \mathrm{kcal}$. RS, in the form of the ingredient Hylon VII, (Ingredion, Bridgewater, NJ, USA), was added prior to cooking. The mandasi was prepared daily for delivery to each subject's home every morning and evening. Children consumed the mandasi under the direct observation of study staff. Caretakers of subjects were encouraged to not alter the child's intake of habitually consumed foods during the intervention.

Measurement of Habitual Dietary Intake 
A weighed food record protocol was developed based on 24-hour dietary recall protocols and a previous weighed food record performed in Malawi. Two local enumerators with a high school education were hired to perform the in-home weighed food record with each subject two times, ideally on a weekday and a weekend day. The enumerators recorded the ingredients and final weight of each recipe that was prepared, and then weighed the amount each child consumed at meals. The enumerators arrived at the subject's home before sunrise and stayed until after the last meal of the day was finished. Records were kept for everything the child consumed including water and the study's intervention mandasi.

The enumerators recorded data in their native language, Chichewa, and nurses fluent in Chichewa and English translated the data. The weighed food records and recipe ingredients were entered in Microsoft Excel. Previous analyses of common dishes consumed in central and southern Malawi was used to establish nutrient content for each recipe (Jaimie Hemsworth, personal communication, iLiNS Project, [30]). Microsoft Access was used to calculate combined nutrient values for the summed portions of each recipe consumed by subjects every day. Consumption of common sauces was accounted for by application of a correction factor based on previous data from a 24-hour dietary survey by this research team, showing that the median ratio of solid:liquid was $1.37\left(25^{\text {th }}\right.$ percentile $0.83,75^{\text {th }}$ percentile 2.27 ) [31].

\section{Dual zinc stable isotope test}

Clinical. This procedure required 8 days to complete and was conducted twice during the study. On the first day fasted subjects arrived at the Chipalonga Health Post with their caretakers at 0600. Baseline stool and urine specimens were collected prior to isotope dosing. To measure zinc absorption, carefully weighed doses of oral zinc stable isotopes were administered with each of the three main meals of the day, and each subject received an exactly weighed amount of $\sim 125 \mu \mathrm{g}{ }^{70} \mathrm{Zn}$, (first 
administration) or ${ }^{67} \mathrm{Zn}$ (second administration). Additionally, each child received $\sim 50 \mu \mathrm{g}$ of the same oral isotope with a morning snack of mandasi. No isotope was given with an afternoon snack of banana or mandasi. The diet given with the stable isotopes was chosen to correspond to the habitual amount of zinc, iron, and phytate consumed in the local area, (i.e. maize porridge, beans, boiled vegetable leaves, mandasi, and bananas). Halfway through the meal or snack small drops of the isotope were delivered by a syringe into the child's mouth, alternating with bites of food. The dose vial and the oral syringe used for isotope delivery were rinsed three times with distilled zinc-free water to ensure complete administration of the isotope dose. All losses from drooling or spit were collected on ashless filter paper for later isotope analysis, and this quantity was subtracted from the measured dose. A blood sample was drawn on each day of isotope administration for measurement of the plasma zinc concentration. This was followed by a peripheral intravenous injection of a precisely measured quantity of $\sim 800 \mu \mathrm{g}$ ${ }^{68} \mathrm{Zn}$. Food intake was unrestricted but systematically quantified on the day of isotope administration. Weighed duplicate diets for each subject were collected on both days of isotope administration. After blending, sample aliquots of these diets were frozen for transport to the University of Colorado Denver for analysis of zinc content. On days 5-8, timed partial urine specimens (>10 mL) were collected twice daily, in the morning and evening, and all stools were collected in zinc free plastic sacks for aggregation into four 24-hour collection periods, representing days 5, 6, 7 and 8. On study day 38 subjects were again brought to the Chipalonga Health Post for the second dual zinc stable isotope administration, followed by an 8 day specimen collection period identical to the first.

Laboratory analyses. Total zinc and zinc isotope ratio analyses were conducted in the Pediatric Nutrition Laboratory at the University of Colorado Denver. Duplicate diets and fecal homogenates were dried in an electric drying oven before ashing at $450{ }^{\circ} \mathrm{C} \times 24$ hours. A few drops of nitric acid was placed on samples and allowed to dry on hotplate set at $90^{\circ} \mathrm{C}$. Samples were again ashed at $450^{\circ} \mathrm{C} \times 24$ hours before quantitative reconstitution in $6 \mathrm{M} \mathrm{HCl}$. Total zinc concentration was measured using atomic absorption 
spectrophotometry fitted with a deuterium arc background lamp (model AAnalyst 400, Perkin-Elmer Corporation, Norwalk, CT, USA). Urine samples were digested using a microwave sample preparation system, (CEM Corporation, Matthews, NC), and Zn subsequently chelated for isotope analyses as previously described [28]. Zinc in digested stool samples was separated from other minerals using a column chromatography technique [32].

Stable isotopic enrichment in urine and fecal samples was determined by measurement of the isotope ratios ${ }^{67} \mathrm{Zn} /{ }^{66} \mathrm{Zn},{ }^{68} \mathrm{Zn} /{ }^{66} \mathrm{Zn}$, and ${ }^{70} \mathrm{Zn} /{ }^{66} \mathrm{Zn}$ using inductively coupled plasma mass spectrometry (Agilent 7700x ICP-MS, Agilent Technologies, Santa Clara, CA) with conversion of enrichment ratios using a mathematical matrix. Tracer enrichment was defined as all the zinc in the sample that was derived from the isotopically enriched tracer preparation divided by the total zinc in the sample [33]. Urine and stool samples were collected immediately prior to the second day of isotope administration and analyzed to correct for any residual ${ }^{68} \mathrm{Zn}$ isotope from the first day of isotope administration.

Fecal starch was isolated from stool specimens with a standard enzymatic method utilizing amyloglucosidase and glucose oxidase, and then quantified with spectrophotometry [33-36].

\section{Data Analyses}

FAZ was calculated as follows; FAZ = enrichment (oral/intravenous) $x$ dose (intravenous/oral) [29]. TAZ (mg/day) from all labeled foods was calculated by multiplying daily dietary zinc intake (mg) by FAZ. EFZ was calculated as follows; EFZ $(\mathrm{mg} / \mathrm{d})=($ Total fecal zinc content of $4 \mathrm{~d}(\mathrm{mg}) \times$ fecal \%enrichment ${ }^{68} \mathrm{Zn}$ ) / (urine \% enrichment ${ }^{68} \mathrm{Zn} \times 4 \mathrm{~d}$ of collection) [37]. Exchangeable zinc pool (EZP) is the estimated size of the body's combined total pools of zinc that exchange with the plasma zinc pool over 3 days. EZP was calculated by dividing the dose of intravenous isotope $\left({ }^{68} \mathrm{Zn}\right)$ infused by the enrichment value at the $y$-intercept of the linear regression of a semi-log plot of urine enrichment data from study days 5-8 after isotope administration [38]. NAZ was calculated by subtracting EFZ from TAZ. 
Anthropometric Z scores were determined using the Anthro 2005 software from the World Health Organization [39]. Summary statistics were expressed as means \pm SD. Analysis of changes after intervention with RS was performed using a paired Student's t-Test. The relationships of total absorbed zinc to dietary zinc intake for the before RS and after RS data as well as differences between the study periods were modeled with linear regression. Differences were considered to be significant if $P<0.05$.

\section{RESULTS}

Of the 20 enrolled subjects, one did not complete the study, one did not receive intravenous zinc on the second day of isotope administration, and one was excluded due to anorexia on the second day of isotope administration, leaving 17 for data analyses (Table 1). None of these 17 subjects reported diarrhea, vomiting or a febrile illness, and all were playful with an unremarkable physical examination on both days of isotope administration. Of the 17 children included for analysis 8 were tested for HIV infection and tuberculosis, with none found to be positive.

The most common foods consumed were cooked maize, rice, common beans, and Chinese cabbage. The most commonly consumed animal source food was small fish. The habitual intake of zinc, based on dietary recalls and nutrient composition tables, was $4.4 \mathrm{mg} / \mathrm{d}$ and contained suboptimal amounts of calcium, folate, riboflavin, retinol, vitamin B12, and vitamin C (Table 2). The phytate:zinc molar ratio of the diet was 34:1. On the days of isotope administration, the phytate:zinc molar ratio was calculated to be 30:1 before the RS and 32:1 after $28 \mathrm{~d}$ of RS consumption.

The average RS content of the mandasi was $10 \%$, resulting in approximately $8 \mathrm{~g} / \mathrm{d}$ of RS consumption. Measurement of starch in fecal specimens before and after intervention demonstrated higher levels of fecal starch among all children, with an average 3 fold increase (Table 3 ). There were no adverse events or complaints associated with the starch intake, including abdominal pain or flatulence. 
No change was seen in FAZ or EFZ following administration of RS (Table 3, Fig 1). NAZ and TAZ were diminished after intervention with RS $(P<0.01)$. Plasma zinc and EZP size were not significantly different over the course of the study.

Linear regression analysis showed total absorbed zinc to vary with dietary zinc intake $(P<0.001)$ and that the slopes and intercepts of the regression lines for the two datasets were not significantly different $(P=0.18$ and 0.30 , respectively) (Figure 2$)$.

\section{DISCUSSION}

These data demonstrate no change in EFZ, EZP, FAZ or TAZ relative to dietary intake after consumption of RS for $28 \mathrm{~d}$, suggesting zinc homeostasis was unaffected by RS in these rural African children. The normal zinc homeostasis among subjects prior to the intervention was unexpected and limits our certainty of the effects of RS in other high risk settings.

This investigation shares a limitation common to studies of interventions for alleviating zinc deficiency in that there is not a known unequivocally accurate biomarker for the determination of zinc status. Subjects in this study were verified to have consumed a diet characteristic for reduced zinc bioavailability $[8,9,26,40]$, and exhibited growth stunting, a common clinical manifestation of zinc deficiency $[2,40,41]$. In our previous work in rural Malawi among children of the same age and similar weight, EZP was $43 \mathrm{mg}$ [7]. However, mean baseline EZP in this study was greater ( $52 \mathrm{mg}, P=0.03$, Student's t-test). EFZ was also lower than was found in our three previous studies of rural Malawian children, in which EFZ ranged from 1.4 to 2 times greater $[7,27,42]$.

Our previous studies have supported the notion that among rural Malawian children there is a high incidence of perturbed zinc homeostasis due to large quantities of EFZ. However, the current study findings did not corroborate this observation. Although we can offer no certain explanation for why 
conservation of zinc and overall zinc status were improved from previous studies, the prior data were collected more than five years ago and recent, unappreciated local improvements in sanitation and treatment of diarrhea may account for these differences. The findings may also be limited by absence of a separate placebo group, but each subject served as their own control, with and without RS as the primary variable. Because our measurements were made at just two points in time, dynamic fluctuations in zinc status during the intervention phase would have been undetectable. We offer the additional caveat that caution should be exercised in extrapolating these findings to other populations, such as ill children, those with food supply insecurity, urban dwelling children, or those consuming alternate diets.

There were significant reductions in TAZ and NAZ after the RS intervention. These reductions were entirely the result of reduced zinc intake measured on the second day of isotope administration (Table 3). We do not believe that these changes are reflective of a direct untoward effect of RS on zinc homeostasis. In fact, the mean TAZ in both periods was well above estimated physiologic requirements, and mean NAZ in both periods was generously positive. Furthermore, while the dependence of TAZ on dietary zinc intake and the variation in intakes between the study periods compromised the ability to draw conclusions from the comparison of TAZ means, inspection of plotted data and linear regression analysis supported the finding that there was no RS effect on zinc absorption (Figure 2). Several dietary factors are likely to have contributed to this decrease in calculated zinc intake. Maize for this study was purchased in raw form and milled locally, where it is suspected that variable milling practices accounted for a measured reduction of $2.2 \mu \mathrm{g} / \mathrm{g}$ in the zinc concentration of maize flour used on the second isotope study day. Additionally, the locally purchased mandasi administered on the first isotope study day had a zinc concentration 3.7 times greater than that of the study RS mandasi given on the second isotope day. An additional unlabeled banana was added to the duplicate test diet on the first day of isotope administration, providing an additional $0.1 \mathrm{mg}$ of zinc. In aggregate it is estimated that these differences 
account for $0.5 \mathrm{mg}$ of the mean reduction of $0.9 \mathrm{mg} /$ day between the two isotope study days. Beyond the immediate effects of these discrete differences in the concentration of zinc in foods given on separate isotope study days, there was also trend towards diminished consumption of food items on the second isotope study day. The mandasis that were added to the diet may well have affected habitual food intake patterns. Mandasi is a highly sweetened fried cake principally containing starch and oil, and in this study provided approximately $300 \mathrm{kcal} / \mathrm{d} /$ subject. It is suspected that mandasi supplanted consumption of normally eaten foods resulting in curtailed zinc intake on the second day of isotope administration and over the course of the study. The observed reductions in maize porridge eaten on the second study day, (mean $\Delta-152 \mathrm{~g} /$ day/subject $P=0.13$ ), are likely reflective of a broader pattern of reduced intake of habitually consumed zinc containing foods over the study's course with consequential reductions in parameters of zinc homeostasis. Future studies should give consideration to fortifying any supplemental food item with micronutrients to avoid a pattern in which a dietary intervention supplants habitually consumed foods causing reduced micronutrient intake.

This investigation is notable for being the first to explore the effects of RS on zinc homeostasis in a pediatric population in rural Africa. Since the population was found not to be zinc deficient on the basis of stable isotope measurements, we are uncertain as to what effect RS might have in a population that is truly zinc deficient. Additionally, this is the first study to describe the use of this particular method for administering a prebiotic. The observation that high amylose maize flour added to a fried cake was consumed avidly without any adverse event was encouraging. In the future this vehicle may allow for the widespread delivery of other prebiotics known to improve enteric microbiota profiles and overall gut health.

\section{Acknowledgements:}


This publication is based on research funded by the Bill \& Melinda Gates Foundation. The findings and conclusions contained within are those of the authors and do not necessarily reflect positions or policies of the Bill \& Melinda Gates Foundation.

The authors would like to acknowledge the support and guidance of Dr. Neil Kennedy, Department of Pediatrics, College of Medicine, University of Malawi, Blantyre, Malawi and Christina Brumme for her help with data entry and dietary analyses.

NFK, MJM, GY, KM and EM designed the study and obtained support. KR, CW, MJM and JW planned the study and obtained necessary approvals. TM, CW, JW, KR, CT and MJM managed the study subjects and collected the data. JW, CW, MIO, KMH and NFK performed the laboratory analyses TM, JW, MJM, KR, LVM and NFK analyzed the data. TD, NFK and MJM wrote the manuscript. All authors have read and edited the manuscript. 


\section{REFERENCES}

[1] Fischer Walker CL, Ezzati M, Black RE. Global and regional child mortality and burden of disease attributable to zinc deficiency. J Clin Nutr 2009; 63: 591-97.

[2] Black RE, Allen LH, Bhutta ZA, et al. Maternal and child undernutrition: global and regional exposures and health consequences Lancet 2008; 371: 243-60.

[3] Brown KH, Peerson JM, Allen LH. Effect of zinc supplementation, on children's growth: a metaanalysis of intervention trials. Bibl Nutr Dieta 1998; 54:76-83.

[4] Prasad AS. Zinc: mechanisms of host defense. J Nutr 2007; 137: 1345-49.

[5] Zinc Investigators' Collaborative Group. Prevention of diarrhea and pneumonia by zinc supplementation in children in developing countries: pooled analysis of randomized controlled trials. J Pediatr 1999; 135: 689-97.

[6] O’Dell BL, Savage JE. Effect of phytic acid on zinc availability. Proc Soc Exp Biol Med 1960; 103: 3046.

[7] Manary MJ, Hotz C, Krebs NF, et al. Zinc homeostasis in Malawian children on a high phytate maizebased diet. Am J Clin Nutr 2002; 75:1057- 61.

[8] Yonekura L, Suzuki H. Effects of dietary zinc levels, phytic acid and resistant starch on zinc bioavailability in rats. Eur J Nutr 2005; 44: 384-91.

[9] Davies NT, Nightingale R. The effects of phytate on intestinal absorption and secretion of zinc, and whole-body retention of Zn, copper, iron and manganese in rats. Br J Nutr 1975; 34: 243-58

[10]Sian L, Mingyan X, Miller LV, et al. Zinc absorption and intestinal losses of endogenous zinc in young Chinese women with marginal zinc intakes. Am J Clin Nutr 1996; 63: 348-53.

[11]Hambidge KM, Mazariegos M, Solomons NW, et al. Intestinal excretion of endogenous zinc in Guatemalan school children. J Nutr 2007; 137:1747-49. 
[12]Griffin IJ, Lynch MF, Hawthorne KM, et al. Zinc homeostasis in 1-4 year olds consuming diets typical of US children. Br J Nutr 2007; 98: 358-63.

[13]Sheng XY, Hambidge KM, Zhu XX, et al. Major variables of zinc homeostasis in Chinese toddlers. Am J Clin Nutr 2006; 84: 389-94.

[14]Griffin IJ, Hicks PD, Liang LK, et al. Metabolic adaptations to low zinc intakes in premenarcheal girls. Am J Clin Nutr 2004; 80: 385-90.

[15]Conlon MA, Kerr CA, McSweeney CS, et al. Resistant starches protect against colonic DNA damage and alter microbiota and gene expression in rats fed a Western diet. J Nutr 2012; 142: 830-42.

[16]Zhu L, Gu M, Meng X, et al. High-amylose rice improves indices of animal health in normal and diabetic rats. Plant Biotechnol J 2012; 10: 353-62.

[17] Ha Aw, Han GJ, Kim WK. Effect of retrograded rice on weight control, gut function, and lipid concentrations in rats. Nutr Res Pract 2012; 6: 16-20.

[18]Le Thanh-Blicharz, Aniola J, Kowalczewski P, et al. Type IV resistant starch increases cecum short chain fatty acids level in rats. Acta Biochimica Polonica 2014; 61: 109-14.

[19]Assisi RF. Combined butyric acid/mesalazine treatment in ulcerative colitis with mild-moderate activity. Results of a multicenter pilot study. Minerva Gastroenterologica Dietologica 2008; 54: 2318.

[20]Morita T, Kasaoka S, Hase K, et al. Psyllium shifts the fermentation site of high-amylose cornstarch toward the distal colon and increases fecal butyrate concentration in rats. J Nutr 1999 suppl; 129: 2081-7.

[21]Bird AR, Vuaran M, Crittenden R, et al. Comparative Effects of a High-Amylose Starch and a Fructooligosaccharide on Fecal Bifidobacteria Numbers and Short-Chain Fatty Acids in Pigs. Dig Dis Sci 2009; 54: 947-54. 
[22]Viveros A, Brenes A, Arija I, et al. Effects of Microbial Phytase Supplementation on Mineral Utilization and Serum Enzyme Activities in Broiler Chicks Fed Different Levels of Phosphorus. Poultry Sci 2002; 81: 1172-83.

[23]Bird AR, Vuaran M, Crittenden R, et al. Comparative effects of a high-amylose starch and a fructooligosaccharide on fecal bifidobacteria numbers and short-chain fatty acids in pigs fed Bifidobacterium animalis. Dig Dis Sci 2009; 54: 947-54.

[24]Bird AR, Vuaran M, Brown I, et al. Two high-amylose maize starches with different amounts of resistant starch vary in their effects on fermentation, tissue and digesta mass accretion, and bacterial populations in the large bowel of pigs. Br J Nutr 2007; 97:134-44.

[25]Sharma A, Yadav BS, Ritika A. Resistant starch: Physiological roles and food applications. Food Rev Int/ 2008; 24:193-34.

[26]Ferguson EL, Gibson RS, Thompson LU, et al. Dietary calcium, phytate, and zinc intakes and the calcium, phytate, and zinc molar ratios of the diets of a selected group of East African children. Am J Clin Nutr 1989; 12: 1450-6.

[27]Manary MJ, Abrams SA, Griffin IJ, et al. Perturbed zinc homeostasis in rural 3-5-y-old Malawian children is associated with abnormalities in intestinal permeability attributed to tropical enteropathy. Pediatr Res 2010; 67: 671-75

[28]Hambidge KM, Krebs NF, Miller L. Evaluation of zinc metabolism with use of stable-isotope techniques: implications for the assessment of zinc status. Am J Clin Nutr 1998; 68: 410-13

[29]Friel JK, Longerich HP, Jackson SE. Determination of isotope ratios in human tissues enriched with zinc stable isotope tracers using inductively coupled plasma-mass spectrometry (ICP-MS). Biol Trace Elem Res 1993; 37: 123-36. 
[30]Thakwalakwa CM, Kuusipalo HM, Maleta KM, et al. The validity of a structured interactive 24-hour dietary recall in estimating energy and nutrient intakes in 15-month-old rural Malawian children. Matern Child Nutr 2012; 8: 380-89.

[31]Standard Operating Procedures for iLiNS-DOSE trial. SOP 120: Form 23 and 23b - Interactive 24hour Dietary Recall and Pictorial Chart. Version number 2.0 (2010-05-27)

[32]Sheng XY, Hambidge KM, Krebs NF, et al. Dysprosium as a nonabsorbable fecal marker in studies of zinc homeostasis. Am J Clin Nutr 2005; 82:1017-23.

[33]Trinder P. Determination of glucose in blood using glucose oxidase with an alternative oxygen acceptor. Ann Clin Biochem 1969; 6: 24-27

[34]Champ M. Determination of resistant starch in foods and food products: Interlaboratory study. Euro J Clin Nutr 1992; 46S2: 51-62

[35]McCleary BV, Solah V, Gibson TS. Quantitative measurement of total starch in cereal flours and products. J Cereal Science 1994; 20: 51-58

[36]McCleary BV, Gibson TS, Solah V, et al. Total Starch Measurement in Cereal Products: Interlaboratory Evaluation of a Rapid Enzymatic Test Procedure. Cereal Chem 1994; 71: 501-05

[37]Krebs NF, Miller LV, Naake VL, et al. The use of stable isotope techniques to assess zinc metabolism. J Nutr Biochem 1995; 6: 292-01

[38]Miller LV, Hambidge KM, Naake VL, et al. Size of the zinc pools that exchange rapidly with plasma zinc in humans: alternative techniques for measuring and relation to dietary zinc intake. J Nutr 1994; 124:268-76.

[39]World Health Organization. WHO Anthro 2005, Software for assessing growth and development of the world's children. WHO 2005.

[40]Brown KH, Rivera JA, Bhutta Z, et al. International Zinc Nutrition Consultative Group, Food Nutr Bull 2004; 25: S99-03. 
[41]de Benoist B, Darnton-Hill I, Davidsson L, et al. Conclusions of the Joint WHO/UNICEF/IAEA/IZiNCG Interagency Meeting on Zinc Status Indicators. Food Nutr Bull 2007; 28: 480-84.

[42]Manary MJ, Hotz C, Krebs NF, et al. Dietary phytate reduction improves zinc absorption in Malawian children recovering from tuberculosis but not in well children. J Nutr 2000; 130: 2959-64.

[43]Institute of Medicine. 2011, Dietary Reference Intakes Tables and Application, IOM, available 2007: http://www.iom.edu/Activities/Nutrition/SummaryDRIs/DRI-Tables.aspx, (August 29, 2014) 
Table 1.

Baseline characteristics of 17 Malawian children studied with resistant starch intervention

\begin{tabular}{|c|c|}
\hline Female Gender & $10(59 \%)$ \\
\hline Age (months) & $44 \pm 6.7$ \\
\hline Collection of clean water for the home (times per day) & $3.4 \pm 1.0$ \\
\hline Weight (kg) & $12.5 \pm 1.2$ \\
\hline Length $(\mathrm{cm})$ & $88 \pm 4$ \\
\hline Weight-for-Height, Z score & $-0.01 \pm 0.7$ \\
\hline Weight-for-age, Z score & $-1.9 \pm 0.76$ \\
\hline Height-for-age, Z score & $-3.2 \pm 0.7$ \\
\hline Hemoglobin, g/dL & $11.1 \pm 1$ \\
\hline
\end{tabular}

Values expressed as either $n(\%)$ or mean \pm SD 
Table 2. Habitual nutrient intake of nutrient of rural Malawian study children* (Median $\left(25^{\text {th }}, 75^{\text {th }}\right.$ \%tile))

\begin{tabular}{|c|c|c|}
\hline Nutrient & Daily amount consumed* & RDA/Al 1-3 child ** \\
\hline Energy (kcal) & $1159(985,1335)$ & \\
\hline Protein (g) & $25(21,31)$ & \\
\hline Fat (g) & $34(27,43)$ & \\
\hline Carbohydrate (g) & $211(178,238)$ & \\
\hline Calcium (mg) & $96(42,158)$ & 700 \\
\hline Folate $(\mu \mathrm{g})$ & $77(54,110)$ & 150 \\
\hline Iron (mg) & $7.3(5.46,8.78)$ & 7 \\
\hline Riboflavin (mg) & $0.43(0.32,0.50)$ & 0.5 \\
\hline Thiamine (mg) & $0.55(0.46,0.68)$ & 0.5 \\
\hline Retinol ( $\mu \mathrm{g}$ RE) & $51(32,122)$ & 300 \\
\hline Vitamin $\mathrm{B}_{12}(\mu \mathrm{g})$ & $0.19(0.09,0.95)$ & 0.9 \\
\hline Vitamin $B_{6}(\mathrm{mg})$ & $0.7(0.6,0.9)$ & 0.5 \\
\hline Vitamin C (mg) & $8.5(3.7,35)$ & 15 \\
\hline Zinc (mg) & $4.4(3.5,5.5)$ & 3 \\
\hline
\end{tabular}

*Data pooled from two weighed food records per subject

**RDA/Al data from the Institute of Medicine (44) 
Table 3. Parameters of zinc homeostasis and status before and after resistant starch intervention in rural Malawian children*

\begin{tabular}{llll}
\hline & Before $\boldsymbol{R S}$ & After $\boldsymbol{R S}$ & $\boldsymbol{P}$-Value \\
\hline Fecal starch, \% of fecal dry matter & $7 \pm 4$ & $20 \pm 10$ & $<0.001$ \\
Duplicate diet zinc intake $(\mathrm{mg} / \mathrm{d})$ & $4.9 \pm 0.96$ & $4.0 \pm 0.66$ & $<0.01$ \\
Fractional absorption of zinc & $0.38 \pm 0.08$ & $0.35 \pm 0.06$ & $<.27$ \\
Total absorbed zinc $(\mathrm{mg} / \mathrm{d})$ & $1.88 \pm 0.56$ & $1.39 \pm 0.27$ & 0.67 \\
Endogenous fecal zinc $(\mathrm{mg} / \mathrm{d})$ & $0.75 \pm 0.36$ & $0.84 \pm 0.37$ & 0.01 \\
Net absorbed zinc $(\mathrm{mg} / \mathrm{d})$ & $1.11 \pm 0.7$ & $0.55 \pm 0.46$ & 0.81 \\
Plasma zinc ( $\mu \mathrm{g} / \mathrm{L})$ & $702 \pm 104$ & $690 \pm 101$ & 0.75 \\
Exchangeable zinc pool $(\mathrm{mg})$ & $52 \pm 12$ & $51 \pm 10$ & 0.1 \\
\hline Exchangeable zinc pool $(\mathrm{mg} / \mathrm{kg})$ & $4.2 \pm 0.9$ & $3.7 \pm 0.7$ & \\
\hline *Data are presented as mean \pm SD; $P$-value determined by paired two-sided Student's t-test
\end{tabular}




\section{Figures}

Figure 1. Endogenous fecal zinc and net absorbed zinc in Malawian children before and after resistant starch consumption for 28 days. Horizontal lines represent the mean values and whiskers are SD. Net absorbed zinc in the habitual diet period $>$ in the period after resistant starch was added $(P=0.01)$.

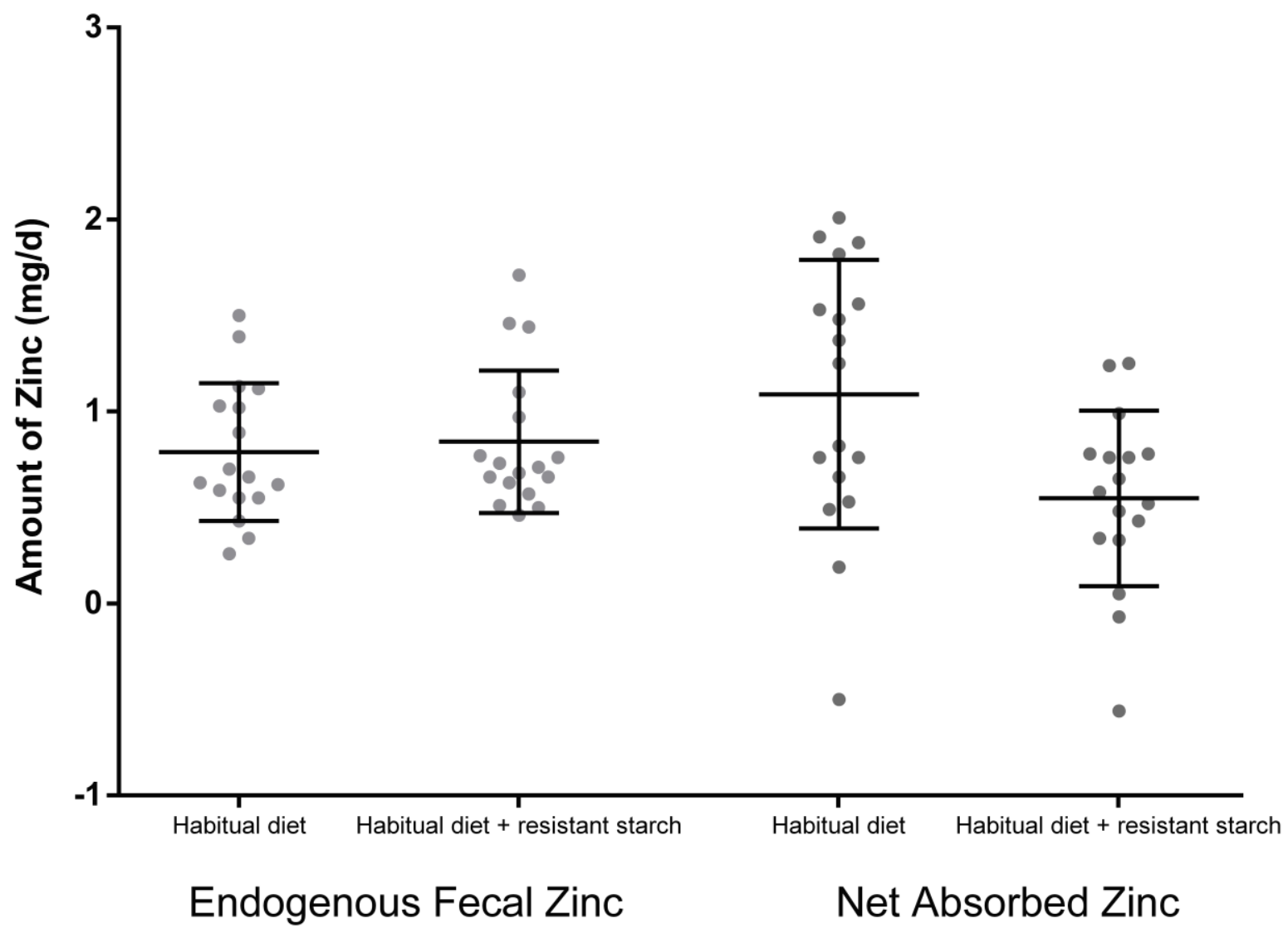


Figure 2. Plot of total absorbed zinc vs. dietary zinc intake for before RS ( $\bullet$ ) and after RS (०) data. Dashed lines represent linear regession lines.

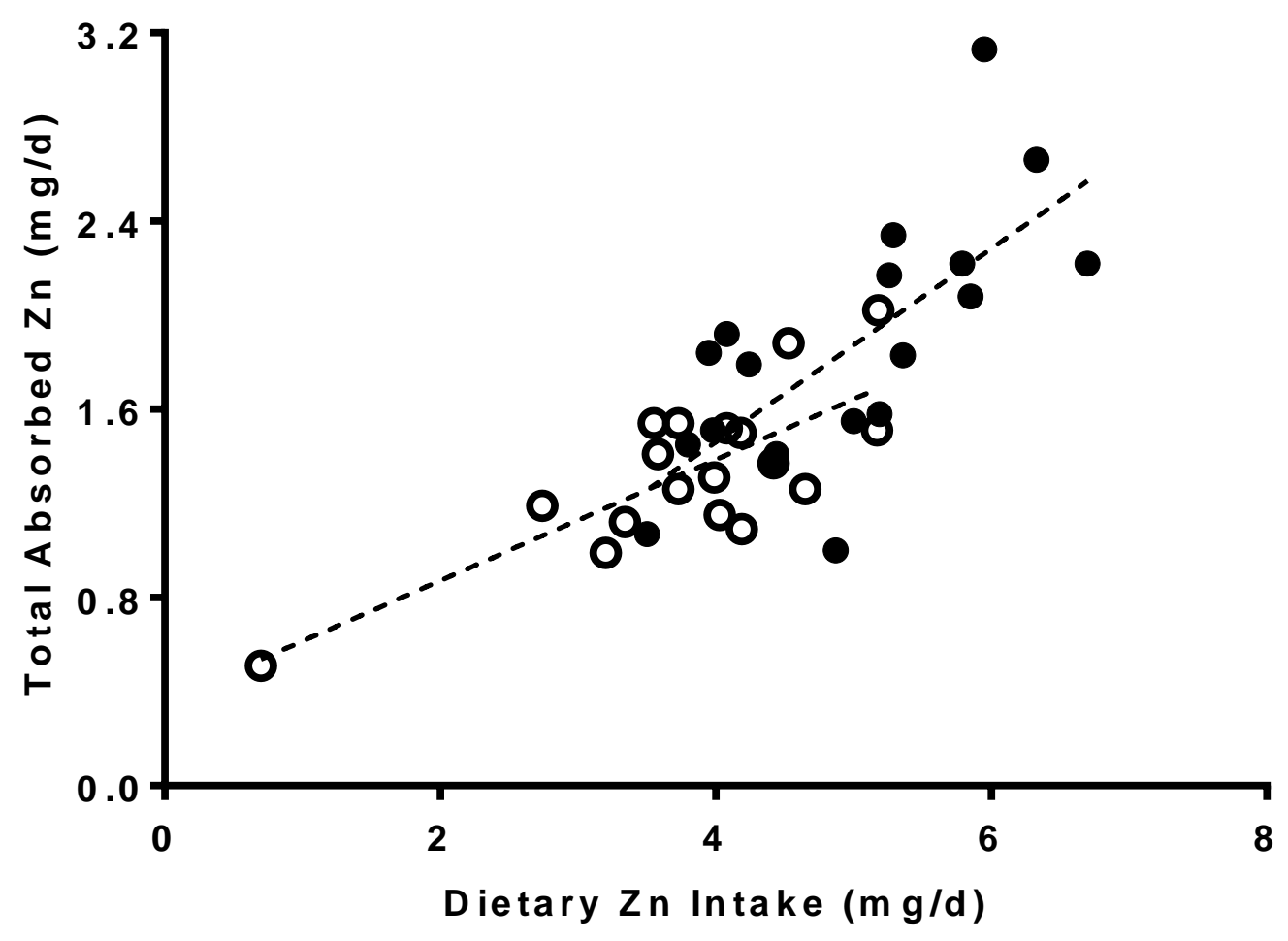

